\title{
Analysis of power and energy losses in power systems of electric bus battery charging stations
}

\author{
Jarosław Jajczyk ${ }^{1, *}$, Arkadiusz Dobrzycki ${ }^{1}$, Michat Filipiak ${ }^{1}$, and Dariusz Kurz ${ }^{1}$ \\ ${ }^{1}$ Poznan University of Technology, ul. Piotorowo 3a, 60-965 Poznan, Poland
}

\begin{abstract}
Two variants of electricity transmission from the Transfer-Switching Station (TSS) to the battery charging station were analysed in the paper. The first variant under analysis referred to the transmission of electricity via a three phase a.c. line with rated voltage of $15 \mathrm{kV}$. In the second variant of electricity transmission, the d.c. line with the working voltage of $1500 \mathrm{~V}$ was used. For both variants, lines and other equipment such as transformers, rectifier system and voltage stabilisation system in the battery charging station were modelled. For both solutions, analysis of energy per annum was conducted depending on the distance of the charging station from the TSS. On top of this, the simultaneous operation of several chargers was taken into account, which would correspond to the case of charging many buses at the same time from a single power line. The paper demonstrates that in the case of the analysed electricity transmission systems in the electric bus battery charging systems it is possible to use a more advantageous solution, which is characterised by reduced power and energy losses.
\end{abstract}

\section{Introduction}

Electrically operated buses are becoming a more and more popular means of transport. The main reason for the use of the electric power in the municipal transport is the carbon efficiency which is of particular significance in densely populated areas (cities). The examples of cities, where such solutions are already in use include: Hamburg, Stockholm, Gothenburg, Vienna, Stuttgart or Geneva. On top of this, electric buses are operated at airports, i.e. places where their range may be relatively small.

The use of the electric buses does not require such high investment outlays as is the case with trams (among other things, the necessity to build tracks). In the simplest variants, it is enough to provide the depot with the charging station. However, such an approach limits the effective use of the rolling stock (the necessity to return to the depot for the charging time, the limitation of the length of lines and operating time due to the capacity of the batteries).

A solution that ensures a fuller use of the electric bus potential is to ensure the appropriate infrastructure that allows for the charging of batteries of the buses as they are in service. The solution is implemented mainly by means of fast charging stations [1-4]. The stations are situated at selected bus stops in such a way as to make it possible for the bus to cover another section of the route after the batteries are charged. One of the three following methods is used to perform the charging process: plug-in charging, by means of a pantograph or the wireless charging $[1,2,5]$. Efficient and correct performance of the battery charging process requires the appropriate powering of the charging station [6-10]. Such a station, depending on the configuration, may be powered with alternating current (a.c.) or direct current (d.c.).

The paper provides the comparison of the methods of powering of the battery charging stations in electric buses depending on the type of the supply voltage (a.c. or d.c.). The structure of both systems was presented, commencing from the TSS and ending with the charging station. The efficiencies of its respective sections were taken into consideration and on this basis, analysis of power and energy losses was carried out during the charging process with the electricity transmission by means of a.c. or d.c. lines.

\section{Power supply for the battery charging station}

In the case of charging of the bus batteries during short stops at bus stops, it is necessary to supply them with appropriately high power which allows for the fast charging $[1,2,3,4,10]$. Such a solution requires the application of a separate power line, especially in the case of locating several charging stations at a single site e.g. at intersections. Two approaches are applied in practical solutions $[1,2]$. The first approach consists in the powering of the charging station by means of a threephase alternating current line (Fig. 1). In this case, after reducing voltage in the TSS from $\mathrm{HV}$ to $\mathrm{MV}$, electricity is transmitted via the medium voltage line. Such a solution requires the provision of the remaining elements of the power supply system within the charging station, i.e.: $\mathrm{MV} / \mathrm{LV}$ transformer, rectifier system, voltage

\footnotetext{
*Corresponding author: jaroslaw.jajczyk@put.poznan.pl
} 
adjustment and charging control system (d.c./d.c.).

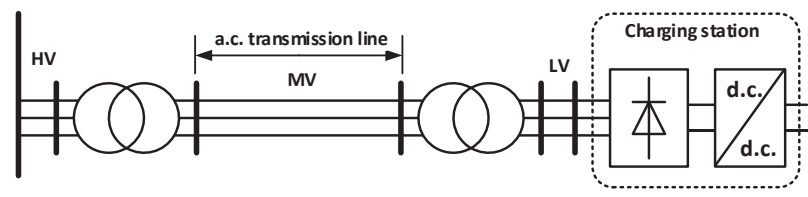

Fig. 1. A.C. line power supply.

In the second method, the direct current line (Fig. 2) is used to transmit electricity. In this case, the TSS, except the HV/MV transformer, also includes the $\mathrm{MV} / \mathrm{LV}$ transformer and the rectifier system. Electricity is transmitted using the d.c. line. The level of voltages is adjusted in the charging station by means of the d.c./d.c. converter, which is also responsible for the charging process control.

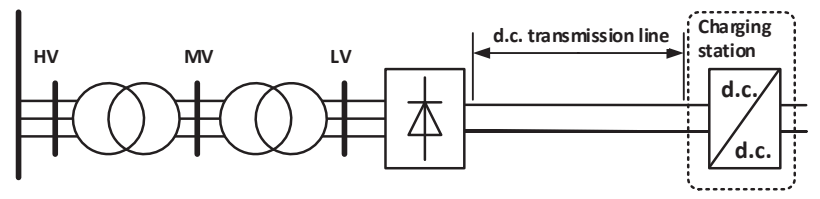

Fig. 2. D.C. line power supply.

In this solution, it is also possible to power the charging station from the tram traction. The chances are that such a solution will be applied in municipal agglomerations, where the transport network including trams, trolleybuses or subway is operative. In order to power the charging station, it is also possible to take advantage of the railway traction network, especially when the bus stop is located close to it and there is no adequate power infrastructure.

\section{Analysis of power and energy losses in power supply systems for battery charging circuits}

Actions related to the natural environment protection in the field of transport, and especially taking into account the issues regarding electric vehicles, cannot be understood as reduction of emissions of pollution into the air exclusively. In this case, an important issue is to strive for the highest possible efficiency of the sources and electricity transmission systems $[6,7,9,11]$. A persistent problem is the issue of optimisation of the system $[2,12,13,14,15]$, which consists, among other things, in the minimisation of the losses related to the transmission and conversion of electricity (rectification, adaptation of the voltage level). While balancing the amount of energy necessary to power an electric vehicle, it is also important to take into account the energy lost along the source-battery route. As well as the thermal losses related to the electricity conversion and flow of current $[6,9]$, in the case of the electricity transmission via lines with higher voltages, it is also necessary to consider the possible losses related to other physical phenomena $[7,9,10,12,16]$.

The subject of analysis in this paper is such a configuration of the power supply system, in which the
TSS is the source. In the case of the charging stations supplied with alternating current, the analysed elements (considered important from the point of view of the transmission efficiency) include:

- the HV/MV transformer located in the TSS,

- the MV transmission line,

- the $\mathrm{MV} / \mathrm{LV}$ transformer located in the charging station,

- the rectifier system in the charging station,

- the voltage adjustment and charging control system. In the case of the DC power supply for the charging station, the elements taken into consideration in the analysis include:

- the HV/MV and MV/LV transformers located in the TSS,

- the rectifier system located in the TSS,

- the d.c. transmission line,

- the voltage adjustment and charging control system.

The above considerations leave out the effect of the charging station equipment which consumes electricity for its own needs (e.g. for active cooling of the converter systems).

The following formula is used to calculate the total power losses in the power supply system (1):

$$
\Delta P=P_{T S S} \cdot\left(1-\prod_{i=1}^{n} \eta_{i}\right)
$$

where:

$\Delta P \quad-\quad$ total power losses of the transmission system,

$P_{T S S}$ - power on output terminals of the power supply point,

$\eta_{i} \quad$ - efficiency of the $i$-th element of the power supply system,

$n \quad-$ number of components of the power supply system (in the issue under consideration $n=5$ ).

Power losses in transmission system $\Delta W$ were calculated using the following equation (2):

$$
\Delta W=\Delta P \cdot t_{r}
$$

where:

$t_{r} \quad-\quad$ time of electricity transmission during a year.

Efficiencies of the respective elements of the power supply system (transformers, converters) were selected on the basis of datasheets. An exception to this is the efficiency of the transmission line. As is known, power losses in the line depend both on the volume of the transmitted power and on the physical parameters of the line per se e.g.: resistivity, geometry or type of the line. In order to calculate the line efficiency $\left(\eta_{\text {line }}\right)$ based on the power losses, the following formula is used (3):

$$
\eta_{\text {line }}=\left(1-\frac{P \cdot \rho \cdot l}{U^{2} \cdot \cos ^{2} \varphi \cdot s}\right) \cdot 100[\%]
$$

where:

$P \quad-$ power transmitted via the line,

$U \quad-$ rated voltage of the transmission system,

$\varphi \quad-$ phase angle of the receiver,

$l \quad-$ length of the transmission line,

$\rho \quad-\quad$ resistivity of the line material, 
$s \quad-\quad$ cross-section of the transmission line.

An assumption was made that the power lines are cable lines, that is, they are dominant in the presently built municipal power lines.

\section{Exemplary calculations of power and energy losses}

Calculations of the power and energy losses were performed for cases of powering of one, two or three stations using a single power line. The assumption in the paper is that the power transmitted to one battery charging station amounts to $150 \mathrm{~kW}$ and 3 stations are powered by maximum one line.

To determine the power losses, formula (1) was used. The assumed efficiencies of the respective components of the charging station power supply system were listed in table 1. The ranges of efficiency were provided for the a.c. and d.c. transmission lines as efficiency value depends on, among other things, the length of the line. The actual values of these efficiencies were calculated in accordance with formula (3). For the calculation purposes, the minimum acceptable cross-section of cables was taken into account.

Table 1. Assumed efficiencies of the respective elements of the transmission system $[1,2,5]$.

\begin{tabular}{|c|c|}
\hline Element & $\boldsymbol{\eta}[\%]$ \\
\hline HV/MV transformer & 99 \\
\hline MV/LV transformer & 97 \\
\hline Rectifier system & 99 \\
\hline $\begin{array}{c}\text { d.c./d.c. voltage adjustment } \\
\text { system }\end{array}$ & 99 \\
\hline $\begin{array}{c}\text { High performance a.c./d.c. } \\
\text { charging station }\end{array}$ & $\begin{array}{c}(99.5 \div 99.9) / \mathrm{km}- \\
\text { depending on the } \\
\text { transmitted power }\end{array}$ \\
\hline $\begin{array}{c}\text { a.c. transmission line } \\
\text { depending on the } \\
\text { transmitted power }\end{array}$ \\
\hline d.c. transmission line
\end{tabular}

Fig. 3 presents the exemplary relative power losses for a situation in which one station is powered. Detailed results of the calculations can be found in the paper by [17]. The obtained results suggest the consideration of energy losses related to the transport of energy to the charging station as potentially small differences in power losses may translate into significant differences in annual energy loss.

In order to analyse the energy losses, it was assumed that each station works occasionally in the 1/6- minute cycle on working days (which represents an annual average of 251 days, 16 hours each) and in the 1/12-

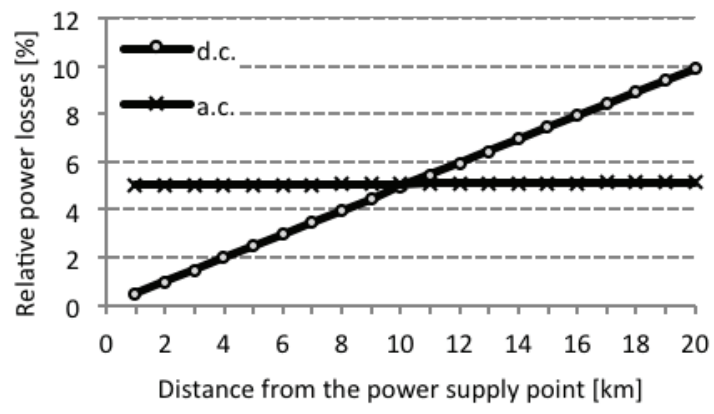

Fig. 3. Relative power losses for the power supply of one station with the capacity of $150 \mathrm{~kW}$, depending on the distance from the power supply point.

minute cycle on holidays (which represents an annual average of 114 days, 16 hours each). On this basis, the average yearly working time $t_{r}$ of one station was determined. These assumptions were made based on the statistical data and average frequency of arrival of a bus to the bus stop $[18,19]$. The paper analyses the energy losses for the distance of the charging station from the TSS located within a radius of $1-20 \mathrm{~km}$.

The results of calculations of annual energy losses depending on the distance from the TSS for two power supply variants (a.c. line and d.c. line) are presented in Fig. $4 \div 6$. The figures present the relationship of these losses in the case of transmission of power amounting to 150 kW (Fig. 4), 300 kW (Fig. 5) and 450 kW (Fig. 6).

Data listed in table 1 as well as the exemplary results of calculations illustrated in Figs. $3 \div 6$ allow for a conclusion that in the case of the a.c. system, the element that generates the highest losses is the charging station and the impact of other factors is much less significant. On the other hand in the case of the d.c. system, the decisive factors include transmission losses related directly to the length of the line and the transmitted power. On top of this, in the case of reduced transmitted power, ( 1 or 2 charging stations powered from the line) it is possible to indicate the distance ranges for which reduced energy losses will be obtained using the d.c. systems.

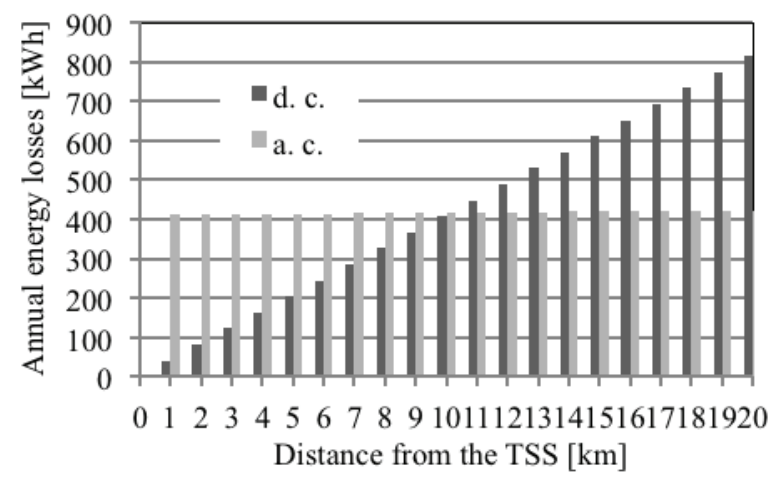

Fig. 4. Annual energy losses for the power supply of one station with the capacity of $150 \mathrm{~kW}$. 


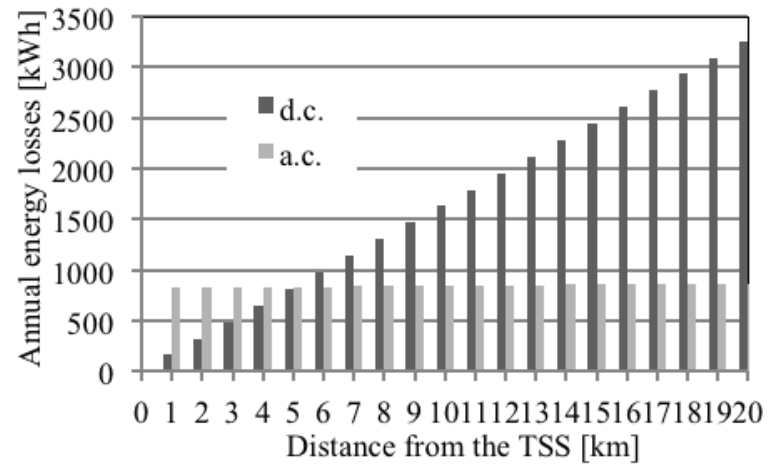

Fig. 5. Annual energy losses for the power supply of two stations with the total capacity of $300 \mathrm{~kW}(2 \times 150 \mathrm{~kW})$.

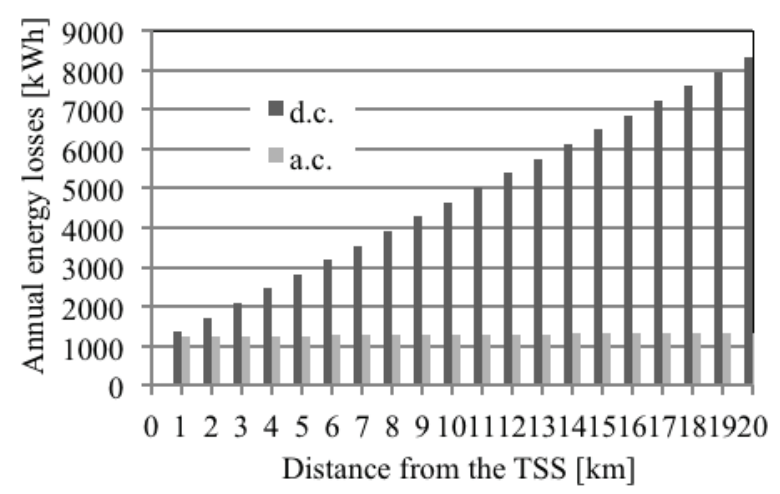

Fig. 6. Annual energy losses for the power supply of three stations with the capacity of $450 \mathrm{~kW}(3 \times 150 \mathrm{~kW})$.

\section{Conclusions}

The paper presents calculations of energy losses for different variants of power supply as the function of distance of the electric bus battery charging stations from the TSS. Simultaneous operation of several chargers was simulated, which corresponds to the case of charging of the batteries of many buses at the same time from a single power line. The results were presented in the graphic form. On their basis, the energy losses during the charging process were compared for the transmission of electricity via a.c. or d.c. lines.

The paper has demonstrated that for the analysed (a.c. or d.c.) electricity transmission systems in the electric bus battery charging systems, it is possible to indicate a more advantageous solution (characterised by smaller power and energy losses, i.e. higher efficiency) using direct or alternating voltage. The choice depends, among other things, on the efficiency of the elements, which are part of the electricity transmission system, the length of the line and the value of the transmitted power.

Analysis of the results of calculations allows for the conclusion that reduced losses are related to the use of d.c. systems for shorter lines and reduced power. On the other hand, in the case of longer distances, it is more advantageous to use a.c. systems. Unfortunately, it is not possible to indicate unambiguously an economically more effective solution. As well as the costs of construction of the infrastructure, it seems necessary to take into account the analysis of potential costs related to energy losses. In particular, this is noticeable in the case systems with reduced capacity (1-2 charging stations), as in the case of the long-term operation, this factor may turn out to be extremely important, considering a systematic increase in the prices of electricity. It is also necessary to remember about the main reason for use of electric vehicles, i.e. the minimization of pollution emissions. Ensuring high effectiveness of the used power supply system indirectly affects the reduction in pollution emissions.

\section{References}

1. M. Rogge, D.U. Sauer, S. Wollny, Energies 8, (2015)

2. S. Bai, D. Yu, S. Lukic, Energy Conversion Congress and Exposition, 1178-1184 (IEEE, 2010)

3. L. Kasprzyk, Eksploat. Niezawodn., 19 (2017)

4. D. Burzyński, L. Kasprzyk, E3S Web of Conferences, 14, 01041 (2017)

5. M. Filipiak, Computational Problems of Electrical Engineering, 1-3 (IEEE Xplore, Sandomierz, 2016)

6. K. Bednarek, Prz. Elektrotechniczny, 84/12 (2008)

7. K. Bednarek, R. Nawrowski, A. Tomczewski, Studies in Applied Electromagnetics and Mechanics, 22, 363-368, (IOS Press, Amsterdam, Berlin, 2002)

8. K. Bednarek, J. Jajczyk, Prz. Elektrotechniczny 85/12 (2009)

9. Z. Piatek, T. Szczegielniak, D. Kusiak, Prz. Elektrotechniczny 87/5 (2011)

10. G. Dombek, Z. Nadolny, Eksploat. Niezawodn. 18, (2016)

11. D. Kurz, Computational Problems of Electr. Eng., 1-5 (IEEE Xplore, Sandomierz, 2016)

12. J. Jajczyk, L. Kasprzyk, Int. Conf. Heat Transfer, Therm. Eng. Environ., 226-231 (WSEAS, Rhodes, 2008)

13. L. Kasprzyk, Prz. Elektrotechniczny 88/7B (2012)

14. J. Jajczyk, Computational Problems of Electr. Eng., 1-3 (IEEE Xplore, Sandomierz, 2016)

15. J. Jajczyk, Prz. Elektrotechniczny 90/4 (2014)

16. W. Opydo, A. Dobrzycki, Electr. Eng. 94 (2012)

17. A. Dobrzycki, M. Filipiak, J. Jajczyk, Poznan Univ. of Technol. Acad. J. Electr. Eng. 92 (2017)

18. Główny Urząd Statystyczny (http://www.gus.gov.pl/ 4.05.2017)

19. http://www.mpk.poznan.pl/, (4.05.2017) 